Article

\title{
Substantiating Energy Justice: Creating a Space to Understand Energy Dilemmas
}

\author{
Nathan Wood ${ }^{1, *(D)}$ and Katy Roelich ${ }^{2}$ \\ 1 Inter-Disciplinary Ethics Applied Centre, Sustainability Research Institute, University of Leeds, \\ Leeds LS2 9JT, UK \\ 2 School of Earth and Environment, Sustainability Research Institute, University of Leeds, Leeds LS2 9JT, UK; \\ k.e.roelich@leeds.ac.uk \\ * Correspondence: eenwo@leeds.ac.uk
}

Received: 27 January 2020; Accepted: 29 February 2020; Published: 3 March 2020

\begin{abstract}
This paper explores the relationships between the moral philosophical foundations and strategic goals of two conceptions of energy justice: the "triumvirate conception" and the "principled approach". We explore the extent to which the goals of these approaches align with their core aims and strategies. Having initially been developed to capture and reflect the values of activist-led environmental justice movements, we find that the triumvirate approach's adoption of a trivalent conception of justice currently lies in tension with its overarching top-down approach. We note that the principled approach does not face the same tensions as the triumvirate conception of energy justice, but would benefit from illustrating the consequences of framing the same energy dilemma with conflicting moral theories. Aiming to ameliorate these limitations and further develop conceptions of energy justice, we outline a case study of hydro power in Hirakud, India and propose a framework which illustrates how using differing theories of justice to conceptualise the same energy dilemmas can result in substantially different normative framings and guidance. We illustrate how this framework, combined with a pluralistic appeal to moral theory, can enable both approaches to draw on a wider range of moral theory to assess energy dilemmas. This in turn provides a broader socio-political backdrop in which to view energy dilemmas. We outline how this backdrop contributes to the creation of a space in which the grievances of those who suffer in relation to energy systems can be heard and better understood.
\end{abstract}

Keywords: energy justice; energy; energy dilemma; moral theory; ethics; just transition; capability

\section{Introduction}

The term "energy justice" can be a source of confusion, as it describes both a research agenda and a set of conceptual approaches. As a research agenda, energy justice has focused on a range of issues that arise in relation to energy systems, from issues of access such as fuel and energy poverty, to issues regarding the extraction, production, and distribution of energy, and how such issues relate to ideas of "justice" and "fairness". The idea of justice in particular has been drawn on in ways ranging from broad and ambiguous interpretation, synonymous with intuitive ideals of fairness, to the application of accounts of justice drawn straight from moral and political theory. Bickerstaff et al. [1] for example, contains a collection of works which engage with justice scholarship at various levels of abstraction to discuss and frame different sets of energy dilemmas, such as fuel poverty, energy vulnerability, nuclear energy, and sustainable energy transitions. Elsewhere, the scholarship has drawn on a diversity of moral theory to develop individual conceptions of energy justice which can be used to frame and respond to a range of energy dilemmas throughout whole energy systems [2,3]. 
In this paper, we focus on two prominent conceptions of energy justice: the conception set out in McCauley, Heffron, Stephan, and Jenkins [2], which we refer to as the triumvirate conception of energy justice (TCEJ), and the conception set out initially in Sovacool and Dworkin [3], Global Energy Justice, which we refer to as the principled approach.

Both approaches share some similarities in that their goals broadly revolve around integrating ideas of justice or fairness into energy policy and decision-making processes [3,4]. However, their use of moral theory to underpin their given conceptions of what the "justice" in energy justice consists of diverges in a number of ways, as do their respective strategies of attaining their individual goals.

We therefore focus on three aspects of these approaches: their use of moral theory to underpin their respective conceptions of energy justice, their overall goals, and the strategies which underpin them. By "strategies", we mean the conceptual outputs that enable the attainment of their respective goals. These might take the form of heuristic frameworks through which to view and inform on energy dilemmas, for example. We posit that tensions between these three facets, to varying extents, are inhibiting the ability of each approach to create a space in which to hear and understand the voices and grievances of those who are subject to the ills of energy systems. By extension, we argue that the absence of this space, to varying extents, inhibits the ability of these approaches to normatively inform energy policy and decision-makers.

When drawing on moral theory to create a new approach, it should follow that the motivating moral theory of an approach should also be embodied in its goals and strategies. Put simply, we can ask if the underlying values motivating an approach to energy justice are reflected in its overall goals and accompanying strategies. This is a pertinent question, since the elaboration and interpretation of any given moral theory or concept will substantially influence how it is structured and operationalised. This in turn dictates whether an approach is successful in creating a useful space in which the grievances of those who are subject to the ills of energy systems can be heard and better understood. Such a space is required if energy dilemmas are to be understood in relation to broader social and political circumstances which might underpin them.

From here, we use the term "moral theory" broadly to refer to the philosophical ideas on which these conceptions of energy justice are based. For example, the triumvirate approach to energy justice describes justice as consisting of distributive, procedural, and recognition-based ideals-broad concepts which find their basis in both moral and political theory [5]. Although such concepts also find their roots in political philosophy, for now, we refer to these collectively as "moral theory". We use this term to describe sets of rules and concepts which allow us to evaluate existing situations through various justice lenses, provide guidance as to what we ought to do in response and which describe structures and goods (and their accompanying distributions) we should use to articulate the normative aspects these issues (Section 3). We expand on these concepts further in the paper, illustrating how different moral theories can be used to create a space in which to explore and understand energy dilemmas and their relationship to people's lives.

Our contribution is not necessarily to advocate for a single approach to conceptualising or articulating energy-related injustice, but rather to provide a framework which enables energy justice scholars to explore, utilise, and critique a wide range of moral theory in reference to energy dilemmas. In particular, our framework provides a means of critiquing the given usefulness and ability of various moral theories to frame energy dilemmas in reference to broader socio-political situations which underpin them. Later, we explain how this ability to frame an energy dilemma within a broader socio-political circumstance is necessary in coming to understand how energy dilemmas come to impact the people and societies they do.

We identify two key areas where approaches to energy justice could be strengthened:

- A stronger outline and discussion of the moral foundations on which the various approaches rest, including how such accounts relate to or conflict with the non-philosophical, strategic aspects of each approach; 
- A broader integration of a range of moral concepts and approaches, which in turn can act as a source of normative guidance and a means of embedding complex energy dilemmas within broader socio-political situations.

The paper is structured as follows. The triumvirate and principled approaches' moral and strategic underpinnings are critiqued and compared (Section 2). Potential short-comings, tensions, and areas which could be further developed are used to motivate a discussion regarding the effective pluralistic use of moral theory in analysing and conceptualising energy dilemmas (Section 3). This discussion is then applied to a case study on the construction of the Hirakud hydro power dam, which illustrates the benefits and limitations of using different moral theories in analysing and framing energy dilemmas and producing normative guidance. In particular, we emphasise that different moral theories may yield significantly different normative outlooks and guidance (Section 4). Based on this case study, we outline a framework regarding the use of moral theory in framing energy dilemmas within a broader socio-political context whilst creating a conceptual space in which to analyse and understand energy dilemmas and the grievances of those who endure them. We then outline how this framework, combined with the adoption of a broad pluralism, can to varying extents help ameliorate the tensions within both the triumvirate and principled approaches to energy justice (Sections 5 and 6).

\section{The world through an Energy Justice Lens}

In this section, we outline the relationships between the underlying moral theory, strategies, and goals of the triumvirate and principled approaches to energy justice.

\subsection{The Triumvirate Conception: Foundation and Theory}

The triumvirate conception of energy justice (TCEJ) has had significant uptake in broader energy justice discourse, being utilised in a growing number of empirical and conceptual works [5-12] (this is not an exhaustive list, the number of works which now utilise the triumvirate energy justice framework is far larger), as well as being the subject of numerous reviews [13-15]. As this paper is concerned with the TCEJ's moral foundations and strategic goals, we focus primarily on conceptual contributions to the approach as opposed to its applications $[2,13,14,16,17]$.

\subsubsection{Moral Theory}

Although the seminal TCEJ paper by McCauley, Heffron, Stephan, and Jenkins [2] refers briefly to work on both environmental and climate justice, the approach most closely resembles Schlosberg's trivalent conception of environmental justice, with McCauley et al. (2013) stating that energy justice is "founded in literature on environmental justice", simultaneously citing Schlosberg [18,19]. The approach consists of a "triumvirate of tenets"; distribution, recognition and procedure, which are also found Schlosberg's (2004) earlier conceptions of environmental justice [2,14] (we were aware of an exploration of restorative justice by Heffron and McCauley, (2017); however, in a following paper, McCauley and Heffron (2018) create a "new triumvirate of tenets (distributional, procedural, and restorative)", although it is still briefly discussed in the paper it is omitted from the triumvirate without explanation. As such, we focus on the initial conception of TCEJ, which has had wider uptake within energy justice discourse).

Based on Jenkins, McCauley, Heffron, Stephan, and Rehner [14] and McCauley, Heffron, Stephan, and Jenkins [2]:

- The distributional aspects of energy justice attempt to capture "where injustices emerge", be this spatially or temporally-in other words, how the benefits and burdens that energy systems produce are distributed through space and over time;

- Recognition focuses on how parties, communities, and individuals are represented and recognised in reference to energy-related events and situations. For example, how indigenous people might be overlooked during the decision-making process of coal mining (See Healy (2018) for an account 
of "embodied energy injustices" in relation to open-pit coal mining in La Guajira, Colombia) or how low-income, fuel-poor households might be under-represented in the development of energy policy (Gillard et al., (2017) posit that the efficacy of policy responses to fuel poverty are curbed through misrecognition). The concept of recognition is largely based on work by Nancy Fraser [20];

- Procedural justice focuses on the processes and means of ameliorating injustices which have been identified, i.e., which procedures and structures could be implemented that incorporate previously misrecognised parties [2,14].

It is worth noting that despite mentioning "just outcomes", "just distributions", and "injustices" a number of times, the authors of this approach do not specify what they take justice to mean or consist of-whether this is through theoretical accounts or testimony and claim-making [2,5,14].

The approach also embodies aspects of cosmopolitan justice, viewing all humans as "world citizens" who are of equal moral worth and standing [16]. This global view of justice is discussed in relation to transboundary energy dilemmas such as nuclear energy and its governing intuitions [16].

This cosmopolitan outlook is reflected in the TCEJ's goals. McCauley, Heffron, Stephan, and Jenkins [2] stated that the TCEJ, "aims to provide all individuals, across all areas, with safe, affordable and sustainable energy." This goal was restated in Heffron and McCauley [17], Jenkins, McCauley, Heffron, and Stephan [13], Jenkins, McCauley and Forman [4], Jenkins et al. [21], and Jenkins [5].

In a much-cited conceptual review, Jenkins, McCauley, Heffron, Stephan, and Rehner [14] outlined how the triumvirate conception offers an opportunity to explore where injustices occur and how these might be avoided or remedied, stating that it is "an agenda that inspires both evaluative accounts and normative solutions" (p. 176). The TCEJ has been framed as a tool for addressing dilemmas through whole energy systems, from production to consumption [13]. Much of the conceptual work on the TCEJ has thus focused on relating these tenets to existing energy dilemmas or methods of informing decision-makers. Jenkins, McCauley, Heffron, Stephan, and Rehner [14] discussed a range of ways in which the principles manifest in practice. For example, procedural aspects of the approach are reflected in processes of mobilising local knowledge and information disclosure. Whilst ideas of mal-distribution and mal-recognition are used to frame a wide range of energy dilemmas, from Germany's energy strategy energiewende, which is framed as producing distributional injustices (this is one of many examples of energy injustices outlined in Jenkins et al. (2016), we recommend viewing the paper for more), to links to the mal-recognition of vulnerable groups in the UK and their vulnerability to fuel poverty.

\subsubsection{Strategies, Goals, and Underlying Tensions}

The TCEJ is argued to have two key strategic benefits which other justice (environment and climate) movements lack [5,16]:

- It provides a way to focus on energy dilemmas in isolation from broader issues;

- Its use as a decision-support tool which offers a means of "embedding justice in policy'".

Both these benefits rest heavily on critiques of environmental and climate justice, in particular that certain aspects of these movements have limited their success in affecting policy $[5,16]$.

Jenkins [5] argued that, "one of the challenges and therefore potential failings of the environmental and climate justice movement is their breadth and lack of clearly defined content." Jenkins outlines how energy justice provides a means of "bounding" out energy dilemmas from the wider range of issues addressed by environmental and climate justice movements [5] (p. 119) (it is worth noting that Jenkins quoted Bickerstaff et al. (2013), who referred to energy justice as a discourse and not the TCEJ in particular). Jenkins [5] then outlined that through adopting a whole systems perspective (viewing energy systems from extraction through to consumption and waste), energy justice can focus on the dilemmas that arise at each stage of a whole energy system in isolation from other societal issues. 
This approach of bounding and separating out particular energy dilemmas from broader discourses is in turn facilitated through the adoption of a top-down methodology [5]. Jenkins argued that this top-down methodology is enabled because of energy justices' "lack of an anti-establishment past" that "opens the door for significant contributions to mainstream policy-making". Jenkins goes on, echoing critique from Heffron, McCauley, and Sovacool [16]:

"Energy justice does so by overcoming what may be identified as the 'naïve' approaches of environmental and climate justice-the presumption that society would support their ideals-focusing instead on embedding justice in policy. This 'top-down' methodology offers the potential for a refined 'practice'" [5] (p. 120).

Although Jenkins followed this with a caveat acknowledging the importance of recognition and activism, the integration of these with top-down approaches represents something of a methodological issue for the TCEJ. The TCEJ is evidently critical of environmental justice's roots-it is true that the movement is broad and does not represent a concise body of literature with clearly defined content-but this is exactly what Schlosberg's conception of environmental justice, on which the TCEJ is largely based, sought to reflect. Schlosberg's trivalent account of environmental justice is an approach which was specifically developed as a space to accommodate and reflect the broad values of activist-led, community-driven movements which accrue to produce a view of global environmental justice $[19,22]$.

Environmental justice movements were motivated in part because the interests and values of marginalised groups were not being reflected and recognised by power-holders and in policy formation $[19,23]$. This is a key reason as to why recognition and a pluralistic conception of justice-the idea that there are many conceptions of "the good" and what is right-are key components of Scholsberg's trivalent approach. They exist to help articulate the idea that different groups will have different values and ways of expressing and articulating those values. So, although TCEJ authors are acutely aware of the importance of recognition and activism, the TCEJ's foundations do not necessarily align with its core strategies of "top-down" policy-making. As a result, the ability of the TCEJ to act as a space to explore energy dilemmas is curtailed.

To be clear, we are certainly not arguing that a greater appeal and accessibility to policy-makers is not beneficial, rather we posit that this method is in tension with the TCEJ's own foundations. Environmental justice movements arose because the voices of multiple community-and activist-led groups were not being heard and reflected in existing environmental policy processes [23].

This tension then brings the approach's goal of providing "all individuals, across all areas, with safe, affordable and sustainable energy" into question. This goal is distinctly prescriptive and top-down. Granted, there is an expansive range of literature which can be used to support the claim that energy, in some form, is an essential part of all human lives, but this is not explored or defined in reference to this goal, nor are definitions of "sustainable", "safe", and "affordable" given in reference to the goal (although these concepts are discussed in TCEJ literature). The goal is rather vague-this might be purposeful, but this is neither stated nor explained. In a sense, the goal embodies traits of mal-recognition, the same dynamics the approach is keen to ameliorate-it embodies the assumption that all communities prescribe to this goal. Broader energy research includes an abundance of accounts of how the attempts of states or power-holders to supply energy to communities who are not consulted results in a range of distributive and recognition issues [6].

It is worth noting the similarities between this goal and the seventh sustainable development goal of ensuring "access to affordable, reliable, sustainable and modern energy for all" [24]. Hillerband (2018) offered a critique of the seventh sustainable development goal, which to a large extent mirrors the goal of the TCEJ to provide all individuals with "safe, affordable and sustainable energy". Hillerbrand argued that this goal fails to adequately capture the interconnections between the environment, humans, and technology, and by doing so inhibits the goal's implementation. Although TCEJ authors do discuss the socio-technical nature of energy systems, they do not attempt to explain or justify their goal of providing safe, affordable, and sustainable energy for all in reference to these concepts or their own trivalent approach. 


\subsection{The Principled Approach: Foundation and Theory}

The principled approach proposed by Sovacool and Dworkin [3] in Global Energy Justice sets out a conception of energy justice as a means to produce "a global energy system that fairly disseminates both the benefits and costs of energy services, and one that contributes to more representative and impartial energy decision-making".

\subsubsection{Moral Theory}

Sovacool and Dworkin lay out a broad exploration of a range of moral theories and conceptions of justice. Sovacool et al. [25] stated, "in very simple terms: [energy justice] attempts to apply principles and concepts from social justice to the global energy system in its broadest sense" (p. 677). The principled approach, like the TCEJ, reflects distributive, procedural, and recognition-based values to justice but these emerge in an eight principled conception of energy justice (in Sovacool et al. (2017), resistance and intersectionality also debut on the list of principles). Before outlining their approach, Sovacool and Dworkin [3] presented and outlined numerous moral theories. Each was then paired with differing energy dilemmas to illustrate how a particular theory might frame and offer normative guidance in ameliorating the issue being discussed. For example, they justified the implementation of a carbon tax through drawing on utilitarian thinkers such as Jeremy Bentham and John Stuart Mill, arguing that such policies might increase the overall utility of a populous. In another chapter, Sovacool and Dworkin discussed energy poverty through a capabilitarian and contractarian lens, referencing the work of Johnathan Rawls, Martha Nussbaum, and Amartya Sen.

Sovacool and Dworkin [3] (p. 374) described their approach:

Our energy justice framework has elements of Kantian ethics, which takes each person as an end. It has libertarian elements of freedom and choice, suggesting that good societies present people with a set of opportunities or substantial freedoms, so they can choose to exercise these or not. It is pluralist about value, holding that capabilities for people are different and also that their own interests vary. It is concerned with justice as recognition, noting that failures of procedural justice can result in discrimination and marginalization. It, also, has elements focused on utilitarianism and welfare, attempting to improve the quality of life for all people, as defined by their capabilities.

The earliest conception of this approach drew almost exclusively on western-centric theories of justice. However, Sovacool et al. [25] (p. 678) illustrated how the principled approach to justice can "tap into the rich insights offered by non-western justice theorists", drawing on such concepts and approaches as Ubuntu, Confucianism, Dharma, and a range of indigenous perspectives of the Americas, as well non-human systems of value.

The principled conception seeks to connect energy policy and technology to eight philosophical concepts: virtue, utility, human rights, procedural justice, welfare and happiness, freedom, posterity, and fairness [26]. The approach then uses these concepts to frame eight energy issues as matters of justice. These principles are underlined by a cosmopolitan foundation, implying that they are universally applicable and reflect the equal moral worth of all humans [27]. The main output of these principles is a conceptual framework consisting of eight values which should be embraced by decision- and policy-makers: availability, affordability, due process, transparency and accountability, sustainability, intergenerational equity, intra-generational equity, and responsibility.

\subsubsection{Strategies, Goals, and Underlying Tensions}

Sovacool and Dworkin [26] positioned the approach as a useful analytical and decision-making tool for framing and responding to energy dilemmas. LaBelle [28] described how the cosmopolitan aspects of this approach allow it to act as a universal, normative check-list for energy decision-making, and this seems very much to be the approach's strategy - to investigate and apply the principles and lessons from a range of works of justice to the complex issues which arise in relation to energy systems. 
This does well to illustrate how framing a specific issue, for example, energy poverty, with a given theory of justice can yield valuable normative guidance and ethical framings, which help move to ameliorate the issue. These framings often prove their use through creating a conceptual space in which the experience of energy poverty can be articulated and better understood. Despite drawing on a range of moral theory, they do not subscribe to one particular notion of the good, and instead subscribe to a pluralistic conception of value which is articulated through the concept of capability (which we expand on later). They illustrate the benefit of using a given theory in assessing a given energy dilemma.

Of course, one could argue that the selection of a given set of values to analyse an energy dilemma might just follow the views of the author, i.e., an author might choose a theory that reflects their existing values and conclusions. However, the importance of theory becomes particularly important when analysing a complex energy dilemma that might not necessarily be directly voiced or seen by a given group. For example, Sovacool and Dworkin [3] drew on an Aristotelian approach to describe why efficiency is key to a functioning energy system. The efficiency of large-scale energy systems will impact people and different groups in many ways, e.g., affordability and reliability. However, these issues might not be voiced in respect to the efficiency of the system supplying them energy, and when airing their grievance might not include any reference to efficiency or the broader energy system. As such, people who interact with any particular part of an energy system will not be creating a local account of justice, which has the language necessary to offer guidance as to how to structure such a system. Through drawing on a particular theory, namely Aristotle's ideas of virtue and happiness, Sovacool and Dworkin [3] were able to outline the value of an energy system aimed towards the betterment of human lives.

Although this exploration of moral theory has resulted in a well-grounded set of principles, we note that the methods presented by Sovacool and Dworkin currently have some limitations. First, although their exploration of justice theory was substantial, there was no clear explanation as to why one theory is used to frame a specific issue and not another. For example, why energy poverty was framed by contractarian and capabilitarian approaches and not libertarian or human rights-based approaches. This poses an issue for their normative check-list-it does not yet explain why it frames one issue with a particular moral theory and not another. Therefore, another level of justification is required to explain the particular selection of moral theory which underpins the values in this energy justice approach. Second, Sovacool and Dworkin selected specific and different conceptions of justice to conceptualise a number of different energy-related issues [3] (pp. 14-15). As a result, the approach does not illustrate how framing the very same energy issue through a different approach to justice can yield drastically different normative conclusions (although they acknowledge that different ideas of justice can and will conflict (see Sovacool and Dworkin (2014) p. 18 and pp. 372, where the authors acknowledge tensions between moral theories and touch on issues of relativism)).

This is a particularly pertinent point which relates to broader energy justice discourse. There is a need to explain why certain moral theories are used over others in the formulation of energy justice approaches. This might be to do with a moral theory's ability to capture the complex interactions humans have with energy systems, or the normative principles which might best guide and frame future energy policy decisions. Regardless of the reason, the selection of moral approaches and concepts will alter the normative outlook and the operationalisation of the approach. Since these approaches are intended to have real-world impacts through use in research, policy, and decision-making, the use of moral theory to provide guidance must be balanced with the ability of a given approach to energy justice to capture and understand the experiences of those who endure energy dilemmas.

\subsection{Summarising both Approaches}

In sum, both approaches, to varying degrees, could be improved by expanding on their engagement with moral theory (Table 1). Both are limited in creating a space through which to analyse or understand 
energy dilemmas, and this limits the efficacy of both approaches in effectively conveying the impact of energy dilemmas on people's lives to policy- and decision-makers.

Table 1. The foundational theory, strategies, goals, and underlying tensions of the triumvirate approach and principled approach to energy justice compared.

\begin{tabular}{|c|c|c|}
\hline & The Triumvirate Approach & The Principled Approach \\
\hline Foundational theory & $\begin{array}{l}\text { The approach primarily appeals to a trivalent } \\
\text { account of justice, consisting of three broad } \\
\text { dimensions: distributive, recognition-based, and } \\
\text { procedural justice. These three dimensions are } \\
\text { used to frame and normatively advise on different } \\
\text { aspects of energy dilemmas. }\end{array}$ & $\begin{array}{l}\text { The approach appeals to a range of } \\
\text { moral theories and perspectives and in } \\
\text { doing so has distilled a range of } \\
\text { principles through which to frame, } \\
\text { analyse, and advise on energy } \\
\text { dilemmas. }\end{array}$ \\
\hline Strategies and goals & $\begin{array}{l}\text { This approach is intended to be used as a } \\
\text { "decision-support tool" and as a means of } \\
\text { embedding ideas of justice in policy via a top-down } \\
\text { methodology. This approach is accompanied by the } \\
\text { method of separately focusing on energy dilemmas } \\
\text { in isolation from broader issues. }\end{array}$ & $\begin{array}{l}\text { A normative check-list to be used by } \\
\text { policy and decision-makers consisting } \\
\text { of eight values: availability, affordability, } \\
\text { due process, transparency and } \\
\text { accountability, sustainability, } \\
\text { intergenerational equity, } \\
\text { intra-generational equity, and } \\
\text { responsibility. }\end{array}$ \\
\hline Underlying tensions & $\begin{array}{l}\text { The triumvirate conception of energy justice } \\
\text { requires additional concepts and framings if it is to } \\
\text { create a useful conceptual space in which the } \\
\text { grievances of those who suffer in relation to energy } \\
\text { systems can be articulated, heard, and better } \\
\text { understood. Without the creation of this space it is } \\
\text { hard to see how the approach can achieve its goal of } \\
\text { better integrating ideas of justice into energy policy. } \\
\text { This difficulty is compounded by the approach's } \\
\text { apparent dismissal of the grass-roots, activist } \\
\text { values on which the trivalent account of justice was } \\
\text { initially founded. The same logic applies to the } \\
\text { justification of their goal of safe, affordable, and } \\
\text { sustainable energy for all. The approach currently } \\
\text { lacks the concepts necessary to justify this goal or } \\
\text { explain why it might relate to the attainment or } \\
\text { avoidance of some conception of justice or injustice. }\end{array}$ & $\begin{array}{l}\text { The approach has provided only a } \\
\text { limited justification as to why it chose } \\
\text { the values and theories it did. Such an } \\
\text { explanation is warranted if the } \\
\text { approach is to justify why such a } \\
\text { combination of theories can produce the } \\
\text { necessary space in which to articulate } \\
\text { and act on grievances which arise in } \\
\text { relation to the energy dilemmas the } \\
\text { approach discusses. }\end{array}$ \\
\hline
\end{tabular}

\section{Moral Theory and a Space for Understanding Energy Justice}

In this section, we outline how certain ways of employing moral theory can help frame and make sense of energy dilemmas. In turn, we explain how these framings help to create the conceptual spaces required for current approaches to energy justice to produce meaningful insights and normative guidance. We outline how different moral theories can paint drastically different normative views of a given situation and subsequently produce different guidance regarding how to articulate or ameliorate an issue.

The vast quantity and diversity of justice scholarship makes it difficult to define exactly what a moral theory or account of justice does or aims to do. As such, we do not attempt to characterise or provide a single definition of justice. A simple means to approach moral theory, as Sandel [29] posited, is to view these theories as presenting answers to the question, "what is the right thing to do?" To answer this question we have to have some sort of account as to what makes something right or wrong. There are two broad and often inter-related perspectives, which offer explanations as to how this might be achieved. Firstly, we might assume that justice is what those who claim to suffer injustice say it is (this is often referred to as "claim making". Walker (2012) offered a useful explanation of this practice). However, we might have situations, especially in relation to energy systems, in which claims of injustice vary in their severity. For example, how can we compare the claims of injustice of a group who have been violently displaced because of a coal mining operation and the claims of a community who argue a nearby wind development spoils their enjoyment of 
nearby landscapes? We take both these issues to be legitimate concerns but here moral accounts of right and wrong (the second perspective), if used pensively, can create spaces and language through which those suffering oppression or hardship, and its severity, can be heard and understood.

The idea outlined in the following section is thus that certain moral theories and ideas of justice can help to create spaces to articulate and understand the impacts of energy dilemmas on people's lives, but with the requirement that these spaces must be broad enough to incorporate a diverse range of voices and conceptions of what is right. This breadth or scope for a diversity of understandings of what is good or just is what we will refer to from here as "pluralism". Pluralism in this sense reflects the idea that there are multiple, overlapping, and sometimes conflicting conceptions of what is right [19]. A useful example and application of pluralism is found in Schlosberg's account of environmental justice $[19,22]$. Schlosberg's account embodies a broad pluralism to create space for the articulation of grievances from a diversity of communities who form the environmental justice movement. Schlosberg noted that many accounts of pluralism arose as critiques of universalist and singular conceptions of justice following arguments regarding the inability of a singular approach to reflect real-life experiences of injustice [19]. Despite this, Schlosberg did not conclude that these theories have no use or value, and instead argues:

We have numerous components and conceptions of justice, and see that different and multiple theories can apply to various issues, cases, and contexts. Using the range of theories available to us, and understanding how they overlap and interact, will illuminate problems more thoroughly. Such an approach will also bring us to see that what we may now understand as disparate issues and movements may be brought together with this shared and overlapping discourse of justice.

‘Schlosberg [19] (p. 173)

\subsection{Justice: Different Theories, Different Answers}

A useful way to describe how moral theories answer the question "what is the right thing to do?" is by observing the good or "metric of justice" through which they frame the world. Saying "good" or "metric" here does not necessarily refer to something material like resources. Although many theories and works focus on resources or wealth, these terms can refer to abstract concepts, such as a human rights, positions of power, or aspects of well-being, such as relationships and dignity. Robeyns and Brighouse [30] framed this as asking, "what should we look at, when evaluating whether one state of affairs is more or less just than another?" Robeyns and Brighouse were referring to metrics of justice (sometimes referred to as "currencies of justice").

Often theories provide a way of describing how societies function and which structures, procedures, and institutions might be required to facilitate this. These might be conceptions of the state, nations, international bodies, and courts, (for example, the study of these institutions, their underlying values, and how citizens interact with one another through them-this falls under "political philosophy"). These institutions are often highly idealised and can embody normative assumptions; however, used with caution, they can add to a theory's ability to frame the world through offering a broader socio-political backdrop in which to embed particular events or situations. As we expand on later, depending on the theory, such "metrics" can be used to capture and reflect both social and political maldistributions within a society.

We compare the framings and insights produced by Jeremy Bentham's utilitarianism and Martha Nussbaum's capabilities approach when applied to the same energy dilemma. It is worth noting that Sovacool and Dworkin [3] drew on both Nussbaum and Bentham in different chapters of Global Energy Justice-it is worth consulting this text to explore how these approaches can be applied to individual energy issues. However, they did not compare and contrast these theories using the same case-which is what we do below as a means of illustrating the variance of normative guidance different moral 
theories can provide when assessing the same energy dilemma. For each approach, we identify the metric of justice and the distribution of the good that they describe.

Some of the conclusions from this case study may seem initially intuitive and obvious, but the point here is not necessarily to provide a conclusion as to whether the project was morally right or wrong, but to illustrate how the use of theory to frame an energy dilemma can yield substantially different framings and insights.

\subsubsection{Bentham's Utilitarianism}

Jeremy Bentham begins An Introduction to the Principles of Morals and Legislation stating, "nature has placed mankind under the governance of two sovereign masters, pain and pleasure. It is for them alone to point out what we ought to do, as well as to determine what we shall do" [31]. Sandel [29] suggested that through this reasoning Bentham concluded that the aim of morality should be to maximise happiness, i.e., the overall balance of pleasure over pain. Actions and events which stand to promote happiness are therefore morally permissible, and ones that do not, are not. As such, the right thing to do in any given situation is the action that will maximise overall pleasure within society (Bentham termed this, "utility").

The metric of justice used by Bentham here is clearly utility, the distribution of which ensures that utility is maximised for the greatest number of people. Sandel noted that Bentham not only intended this logic for decisions made by individuals, but also by legislators and policy-makers [29]. These ideas, in theory, could therefore lend themselves to the assessment of many issues pertinent to policyand decision-making themes in energy justice. However, utilitarianism has been heavily criticised by numerous scholars for its lack of attention of individual rights and its ability to effectively articulate all moral actions into a single metric [29].

It is worth noting that there are other approaches to utilitarianism that are more accommodating of individual rights and the unique value of different activities. For example, John Stuart Mill's approach to utilitarianism argued that liberty is of upmost importance to the individual and that utility should be maximised over time. Mill also argued that not all sources of pleasure are commensurable but that some sources of pleasure-"'higher pleasures"-are better than others [32,33]. For simplicity, this section draws solely from Bentham's utilitarianism to inform our comparison below. However, using Mill's approach to frame a given event or situation would yield different normative conclusions and guidance (Mill's utilitarianism would consider liberty of individuals to have more weight relative to overall aggregate utility) from both Bentham's utilitarianism and Nussbaum's capability approach (which we outline next), as would any other approach to justice.

\subsubsection{Martha Nussbaum's Central Human Capabilities}

Martha Nussbaum's account of central human capabilities provides a partial theory of justice through which to frame the world. The term "partial theory of justice", describes a theory that can explore certain injustices relevant to its prescriptions but cannot specify what to do once these prescriptions are fulfilled [34]. The approach focuses on what people are able to do and be. This indicates that each person must be viewed separately rather than on an aggregate level (this is converse to Bentham's utilitarianism) [35]. Nussbaum [36] based the concept of capability on the freedom to achieve a range of "functionings". Functionings, in turn, are defined as the ability to do and be things which humans have reason to value. This can range from something fairly objective, such as being free from illness (i.e., the capability of bodily health), to the abstract concepts of political and democratic participation (i.e., the capability of political control over one's environment).

The approach focuses on capabilities as ends in and of themselves, because the means for one person to achieve the same level of capability as another might be substantially different. For example, it might require significantly more resources for a less mobile person to gain the same level of bodily integrity as a more mobile person. Therefore, the approach foremost focuses on capability, as opposed to the distribution of resources. Nussbaum argued that the state should ensure each citizen meets 
minimum threshold in each of a predefined list of capabilities: life, bodily health, bodily integrity, sense, imagination, and thought, emotions, practical reason, affiliation, other species, play, and control over one's environment. This is an adapted and shortened version; the full account can be found in Nussbaum [36] (pp. 78-80).

In the case of this theory, the metric proposed is "capability", the distribution is one which ensures a minimum level of capabilities for all. If this level is not attained, it might reflect that a claim to justice exists [37]. This minimum threshold, however, can be quite high or equal for all if it has reason to be. For example, one might argue that the capability of political participation must be equal in all to ensure that a democracy functions properly and fairly.

\section{A Case of Hydro Power: Applying Theory to Produce a Socio-Political Framing}

The moral theories outlined above will offer different framings of both the benefits and burdens of events and situations which occur in relation to energy dilemmas. A common example of an energy dilemma is the construction of a hydro power dam, which has the potential to yield a high output of low-emission, renewable energy and to manage flooding in vulnerable areas, yet often involves the mass displacement of local populations and extensive ecological damage. When introducing the concept of utility, Sovacool and Dworkin [3] briefly drew on the example of the Hirakud Dam in Orissa, India. They noted the dam yielded a number of benefits such as helping to mitigate flood risks, providing irrigation for 75,000 square kilometres of crop land, and the production of $207.5 \mathrm{MW}$ of hydroelectricity [3]. However, they also noted the costs of the dam's construction; the permanent flooding of 600 square kilometres of land and the subsequent relocation of 150,000 people from 22,000 families - many of whom had complained about the project but had been overlooked. Those being resettled faced a number of risks, including marginalisation in their new homes, unemployment, and lack of access to common resources [38]. An important dynamic within many of these issues is that certain groups and people are more vulnerable than others. For example, women in particular face loss of livelihoods as a result of dislocation and are often faced with more precarious and dangerous sources of income [39]. Infants and the elderly are also affected heavily by dislocation [38].

The moral theories outlined above will offer different framings of both the benefits and burdens of events and situations which occur in relation to energy dilemmas. A common example of an energy dilemma is the construction of a hydro power dam, which has the potential to yield a high output of low-emission, renewable energy and to manage flooding in vulnerable areas, yet often involves the mass displacement of local populations and extensive ecological damage. When introducing the concept of utility, Sovacool and Dworkin [3] briefly drew on the example of the Hirakud Dam in Orissa, India. They noted the dam yielded a number of benefits such as helping to mitigate flood risks, providing irrigation for 75,000 square kilometres of crop land, and the production of 207.5 MW of hydroelectricity [3]. However, they also noted the costs of the dam's construction; the permanent flooding of 600 square kilometres of land and the subsequent relocation of 150,000 people from 22,000 families - many of whom had complained about the project but had been overlooked. Those being resettled faced a number of risks, including marginalisation in their new homes, unemployment, and lack of access to common resources [38]. An important dynamic within many of these issues is that certain groups and people are more vulnerable than others. For example, women in particular face loss of livelihoods as a result of dislocation and are often faced with more precarious and dangerous sources of income [39]. Infants and the elderly are also affected heavily by dislocation [38].

Evidently, this project yielded both substantial costs and benefits. It is important here to note that framing such a complex situation with different moral theories will not necessarily yield a clear answer to whether or not a project was normatively the "right thing to do", but will offer a perspective which might help inform or consult people on a decision or broaden our understanding of the situation at hand. So far, we have outlined a number of statistics and consequences without any normative framing (except perhaps our own intuitions). Drawing on a set of moral theories will likely create or change our perspective on the normative content of the statistics. 
Sovacool and Dworkin noted that from a utilitarian perspective, particularly Bentham's, if the overall contribution to utility outweighs the loss then the project is worthwhile. Sovacool and Dworkin did not endorse the project themselves because of this conclusion, but rather stated what those of a utilitarian disposition might conclude. As Sovacool and Dworkin did, we can imagine the thought process of these utilitarians. The relocation and overlooking of the views of 150,000 people from 22,000 families would likely be a source of substantial disutility, foremost for those having to resettle, but perhaps too for the conurbations which may have struggled to receive them. For the families, it may well have meant the severing of ties to treasured landscapes, particular ways of life, sources of income, friends, and more distant relatives. To a Benthamite utilitarian, these costs would all translate into varying losses of utility. The benefits the project yielded, perhaps agricultural gains, the mitigation of the devastating impacts of floods, and the production of energy and the activities this subsequently enables, would yield gains in utility. The fact that different individuals might suffer more or less depending on their social background, gender, and age is not accounted for in this approach and these gains might not necessarily have been obtained by the resettled individuals, but a Benthamite would only be concerned with the overall gain or loss of utility within a wider population. Thus, if these benefits represented a gain in utility of the population overall then they would argue that undertaking the construction of the Hirakud dam was the right thing to do.

The above information can, of course, be reframed through a different moral lens, and changing this moral framing may yield substantially different outlooks and judgements. Framing the above through a capabilities lens does just this. The costs presented by the Hirakud dam can be framed in reference to Nussbaum's list of central human capabilities.

It is clear that many people's capabilities were compromised throughout this process. For example, the act of ignoring the complaints of those being forced to resettle might act to violate the capability of political control over one's environment. It is evident that this project and the subsequent relocation of many people was not a voluntary choice. Such a circumstance may well have reduced political capabilities of those being forced to resettle, and indeed their capability of bodily integrity. A number of other capabilities might have been impacted by resettlement, the capability of affiliation would be impeded as resettled communities become fragmented from one another. Simultaneously, the resettlement process might have taken a greater toll on more vulnerable groups, for example, the elderly and less mobile, and such situations would likely result in the impairment of their capability of bodily health.

The dam simultaneously offered many means of capability enhancement. As outlined, the dam yielded a number of benefits, including flood mitigation, extra water resources, and electricity. All of these benefits would likely have resulted in the enhancement of many people's capabilities. The avoidance of severe floods would have prevented the deprivation of many capabilities, such as bodily health, affiliation, and even life. The extra water resources will likely have increased food security in certain areas, which will have promoted numerous capabilities directly and indirectly. For example, bodily health depends in part on access to food and is essential for one to properly affiliate and engage in society. The electrical output from the dam is likely to have enhanced a number of capabilities. In being a source of both heat and lighting, it will have enabled many activities, for example, enabling children to study in the evenings, thus enhancing capabilities such as practical reason.

The above benefits, however, would only be justifiable if those affected by the dam met a given threshold level of capabilities, which does not appear to be the case [40] (the capabilitarian perspective focusing on the lives of individual people, treating them as ends, would likely be opposed to the way in which people's threshold levels of capabilities were traded to the benefit of others. This is not to say that the capability approach does not favour limiting the capabilities of some for the benefit of others, if those people being limited have capability levels well above the sufficient threshold). As a result, the initial assessment as to which aspects of a situation are voiced or framed as an injustice is going to differ depending on the moral frame which is used. It becomes clear that switching theories to analyse this event is likely to yield different conclusions as to which aspects of the project related to 
justice. Understanding the project through a metric such as capabilities enabled us to see which aspects of people's lives stood to be enhanced or compromised by the dam's construction. Subsequently, this approach can provide insights on alternative ways of delivering the dam or alternatives ways of meeting the goals of the dam (i.e., electricity, flood alleviation, and irrigation resources) that do not compromise these capabilities or that meet them in different ways.

The utilitarian approach takes a conceptual birds-eye view of events providing insights on an aggregate level, whilst the capability approach enables the probing and conceptualisation of events which happen on a personal level. This dynamic feeds into the question of which moral theories lend themselves best to creating a space in which to capture, conceptualise, and articulate the energy-related injustice which energy justice frameworks seek to frame and ameliorate. In certain cases, a large-scale energy project might be deemed necessary because its benefits outweigh its costs. However, this does not imply that this event and its consequences should be explored only through an aggregate lens. The complexities and nuances of such a project might better be explored through a different lens.

\section{Lessons for Energy Justice}

In using multiple theories to frame an issue (Table 2), a conceptual space begins to emerge in which the impacts of an event on people's lives and broader society can be explored in reference to certain values and socio-political circumstances. The circumstances provide a framing, or "socio-political backdrop", in which to contextualise the construction of the dam. A space was thus created which helped identify possible underlying situations which meant certain groups were already more vulnerable to this type of energy dilemma. The capabilities approach offered unique insights on the impacts of the dam on individual people's and communities' lives. Furthermore, the approach pointed towards existing deprivations which likely compounded people's vulnerability to the burdens of energy dilemmas. Simultaneously, the utilitarian framing offered insights into the likely logic employed by the decision-makers. Importantly, this broad conceptual space is not just for academics and decision-makers to probe historic energy dilemmas, but can be drawn on as a space for the testimonies and voices of those who currently endure such dilemmas to be voiced and better understood.

Table 2. A comparison of the normative framings, insights, and guidance produced by separate capabilitarian and utilitarian framings applied to the case study of the Hirakud dam.

\begin{tabular}{|c|c|c|}
\hline & Capability Frame & Utilitarian Frame \\
\hline Scale & Community and Personal Level & Aggregate "Bird-Eyes" Lens \\
\hline Normative framings & $\begin{array}{l}\text { The capability approach offered insights into the } \\
\text { dam's impacts on specific aspects of people's lives. } \\
\text { Through focusing on individual people's or } \\
\text { communities' existing levels of capability the } \\
\text { approach was able to highlight how certain } \\
\text { demographics and groups might be more } \\
\text { vulnerable than others to adverse impacts of the } \\
\text { dam's construction through existing } \\
\text { capability deprivations. }\end{array}$ & $\begin{array}{l}\text { The utilitarian framing focused on the aggregate } \\
\text { impacts of the dam's construction on the overall } \\
\text { utility of the stakeholders. The outcome of the } \\
\text { dam's construction was therefore assessed based } \\
\text { on whether it increased the utility of the overall } \\
\text { affected population. Individual issues, such as } \\
\text { relocation, flood mitigation, habitat destruction, } \\
\text { were only weighted based on their overall impact } \\
\text { on aggregate utility. }\end{array}$ \\
\hline $\begin{array}{l}\text { Normative insights } \\
\text { and guidance }\end{array}$ & $\begin{array}{l}\text { The approach provided a means of identifying a } \\
\text { diversity of groups which needed to participate } \\
\text { earlier in the decision-making processes. } \\
\text { Simultaneously, the approach offered a means of } \\
\text { articulating and justifying which aspects of dam's } \\
\text { construction were normatively problematic. } \\
\text { Through identifying how certain groups or people } \\
\text { may be more vulnerable than others to certain } \\
\text { impacts of dam's construction, the capability } \\
\text { approach offered insights into which issues and } \\
\text { measures could be focused on or implemented in } \\
\text { order to mitigate capability deprivation. }\end{array}$ & $\begin{array}{l}\text { The broad and aggregate framing the utilitarian } \\
\text { approach produced a retrospective insight into the } \\
\text { logic and reasoning likely employed by the } \\
\text { decision-makers involved in the dam's } \\
\text { construction. This framing offered an insight as to } \\
\text { how the impact of a project can be assessed, but } \\
\text { more so, in conjunction with a capabilities-based } \\
\text { framing, highlighted the flaws and important } \\
\text { circumstances which can be overlooked by taking } \\
\text { such an aggregate "birds-eye" view of a large-scale } \\
\text { energy project. }\end{array}$ \\
\hline
\end{tabular}




\section{A Framework for the Pluralistic Use of Moral Theory}

Here, we draw on the above case study to construct a framework outlining how a pluralistic use of moral theory can be drawn on to contextualise and explore energy dilemmas in reference to broader socio-political issues which might serve to underpin and exacerbate energy dilemmas. We later explain how this framework can be used to strengthen both the TCEJ and principled approaches to energy justice, particularly in reference to the methodological issues outlined in Section 2.

In the case study, we noted that both approaches were applied to the same situation, yet enabled a theoretical probing on different levels and at different depths, providing different normative conclusions and framings. These framings entailed viewing a given energy dilemma in relation to external structures, principles, and norms, as outlined by the particular theory being used. These components can combine to produce a socio-political backdrop in which to embed and understand an energy dilemma within a broader context. Figure 1 illustrates this process, showing how energy dilemmas can be framed by moral theories or approaches to yield valuable normative guidance and insights, and subsequently illuminating existing social and political issues, which intersect with an energy dilemma. Providing a view of an energy dilemma framed within a broader situation can enable researchers to explore related and underlying socio-political situations, which may have been previously concealed. In turn, exploring this broader framing can offer a greater variety of normative insights, which can be used to guide decision-making processes. More importantly, perhaps, this social and political backdrop can be used to highlight particular groups or societies which have been overlooked within decision-making processes, i.e., those who may be deprived of the things a given theory holds valuable. Of course, this alone will not inform on the experience of certain groups, but at the very least it can highlight the value of enabling these groups to participate in future decision-making processes.

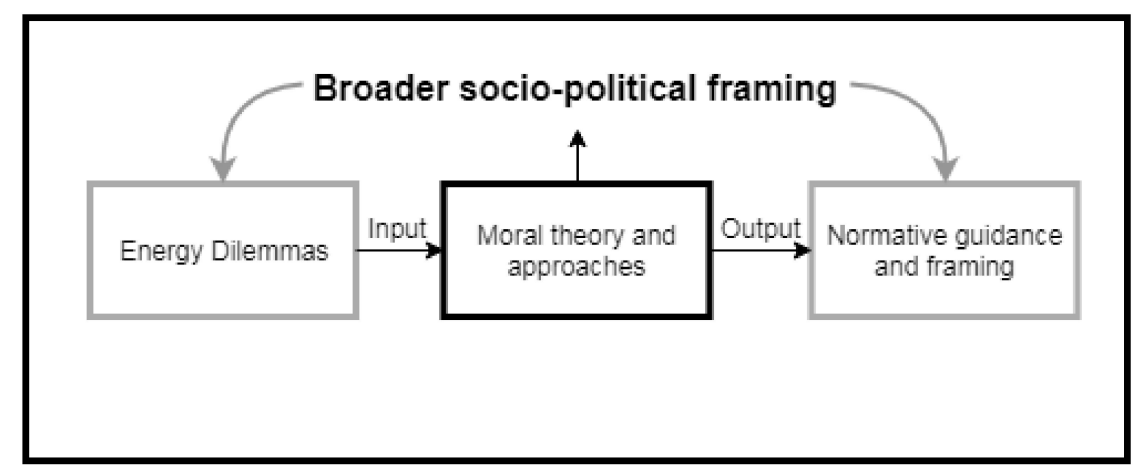

Figure 1. A framework for framing energy dilemmas in relation to moral theory, yielding normative framings and guidance whilst embeding the energy dilema within a broader socio-political back drop.

Drawing on additional theory to explore energy dilemmas allows for a broadening of the socio-political backdrop in which energy dilemmas are embedded. When thinking about the case of Hirakud dam, we might firstly think of it in isolation from other socio-political circumstances. However, when these events are viewed through different moral lenses, a set of socio-political circumstances becomes illuminated. Take, for example, the mass resettlements. Initially, this might be viewed as a symptom completely dependent on the construction of the dam. When viewed through a particular moral theory, in this case the capabilities approach, the resettlements are seen to be a symptom of an underlying and already existing deprivation of political capabilities. The dam's construction and the mass resettlements acted to exacerbate this already existing deprivation. Thus, the impacts of this particular event become clearly embedded in a broader socio-political setting, revealing opportunities and insights that might help mitigate such deprivation in the future.

A pluralistic approach to using moral theory provided a multi-dimensional view of an energy dilemma. In the case study, Bentham's utilitarianism gave a potential insight into the viewpoints of 
the decision-makers- that being one based on making decisions on aggregate. When contrasted with the capabilities view of those affected by the dam's construction, shortcomings with such top-down decision-making processes became apparent. The case study therefore did not just yield normative insights into those who were affected by the dam's construction, but also offered an insight into the potential flaws embodied in the decision-making processes preceding and during its construction.

Listening to the voices of those suffering these events can go some way in explaining how these situations become unjust. However, energy systems are complex and expansive and no one set of voices (or theories) will be able to articulate and reflect the complexity and scale of such circumstances alone. The pluralism we propose therefore does not just embrace the idea that many conceptions of justice and "the good" exist; it also creates space for these complex energy dilemmas to be analysed through multiple moral framings and approaches. This can help link and articulate these events and voices together over various scales, creating an overview of energy dilemmas embedded in larger social and political systems. This is something that seems incredibly pertinent if energy dilemmas are to be addressed using a whole-systems approach and also raises questions regarding the extent to which we can "bound out" energy dilemmas from broader issues.

\section{Implications for TCEJ and the Principled Approach}

In Section 2, we outlined a number of tensions which, in different ways, inhibited the abilities of both the TCEJ and principled approach to create a space in which to articulate and understand the impact of energy dilemmas on those who suffer them. This section therefore outlines how the above framework and pluralistic appeal to moral theory can help ameliorate these issues.

Firstly, adopting a pluralistic approach to the use of moral theory would strengthen the TCEJ, through enabling it to draw on and integrate a broader range of moral approaches and concepts. As the case study illustrated in Section 3, being able to outline which aspects of a situation or event contribute to a communities' or persons' experience of injustice can provide valuable guidance as to how to ameliorate a given situation. This exercise would also prove useful in exploring the TCEJ's goal of providing safe, affordable, and sustainable energy to all through a moral frame. It would enable triumvirate scholars to ground and detail why this goal is of moral significance, by framing energy access by the components or ideas of justice this goal helps deliver and the features of injustice it helps ameliorate.

Moral theory has been drawn on in similar ways within broader energy justice discourse. For example, Day et al. [41] conceptualised energy poverty through a capabilities lens, enabling them to explore and articulate which important aspects of a person's life might face deprivation because of limited access to energy. Day et al. found that the adoption of a capabilities approach helped broaden traditional European conceptions of fuel poverty, which are limited to thermal comfort and health, to encompass wider impacts of energy poverty, such as the deprivation of social respect and the ability to maintain relationships [41]. The latter impact is echoed empirically in analysis by Middlemiss et al. [42] of people who have experienced fuel poverty. Wood and Roelich [43] drew on the capabilities approach and Day et al.'s framework to articulate issues of climate change mitigation in terms of well-being. Approaches which draw on moral theory in this way help provide the normative guidance that the triumvirate conception seeks to produce. They do so through offering language through which to articulate the concerns and grievances of those who endure a range of energy dilemmas. The adoption of a broad pluralism into the TCEJ would enable the approach to integrate and draw on a broader array of existing justice literature without having to subscribe to a defined set of values.

Adopting a pluralistic use of moral theory would also go some way in helping to alleviate the tensions between the TCEJ's top-down initiatives and its underlying foundational ideas of justice. With the goal of "embedding justice" in policy, the TCEJ's aims reflect a concern with enabling policy-makers to understand and operationalise ideas of justice-or to create spaces in which people's conceptions of justice can be understood. Integrating a pluralistic approach would enable the TCEJ to acknowledge the importance of its triumvirate, whilst drawing on other moral accounts to explore how top-down 
policy strategies can come to embody ideals of distribution, recognition, and procedure. Although the theories we discussed in this paper are more likely to be described as distributive theories of justice, the TCEJ could draw on this approach by appealing to theories of procedural justice or theories of democracy (certain theories are often described separately as either distributive, recognition of procedural theories of justice. However, in some cases it might be more accurate to describe them as sitting on a spectrum, with certain theories sitting between these three dimensions of justice. For example, a number of Nussbaum's central capabilities embody aspects of recognition and procedure. We are thankful to an anonymous reviewer for prompting us to think about this further). Recognising the value of certain theories can also assist in distilling these concepts into useful tools or heuristics which can guide policy-making decisions. As such, a broader, pluralistic use of moral theory would enable the TCEJ to maintain its core tenets through developing its own foundation around them.

It is interesting here to note a study by Milchram et al. [44], who drew on the TCEJ to explore the values and conflicts which underpin public debate on smart grids. Reviewing a number of Dutch and British newspaper articles, they found that a number of values, such as sustainability, transparency, control, privacy, and security, are all associated with the implementation and operation of smart grid systems. Subsequently, they recommend that energy justice needs to be broadened to include such values. It is interesting to note, therefore, that such values are reflected in numerous existing works of moral theory [45-49].

Our earlier concerns regarding the principled approach were that it was yet to explain why it drew on one theory of justice over another when framing a particular energy dilemma, and secondly, that it did not explore the implications of framing the same event with differing theories. Given that the approach's principles were developed from an original survey of literature, it does not face the same foundational tensions between its philosophical grounding and its strategic initiatives. However, we found that the beneficial probing of literature that Sovacool and Dworkin [3] lay out can be enhanced through providing broader analysis of the same energy dilemmas through using opposing (or at least differing) moral theories. Certain theories will be able to capture and articulate the impact of energy dilemmas on people's lives more powerfully than others and exploring this can help justify why we might draw on one theory over another in developing guiding principles for decision-makers.

The above case study also serves to illustrate the relativism embodied in certain accounts of justice; whether community-based or singular accounts, it illustrates that different voices and theories will embody and reflect different and sometimes conflicting values. There are still challenges to overcome in this respect. Assessing which accounts of justice are best suited to evaluating a particular set of circumstances can represent a normative judgement in itself. Regardless, using multiple theories of justice can serve to highlight and explain these differences, as well as act as guides in deciding which set of values might best be drawn on when analysing an issue. This is essential when discussing large-scale transboundary energy dilemmas such as climate change, which affect a diversity of communities who each have their own value-sets and concerns.

\section{Conclusions}

To summarise, through comparing and contrasting both the triumvirate and principled approach to energy justice, we revealed a number of theoretical and methodological limitations. We argued that the adoption of a broad pluralistic use of moral theory would enable the utilisation and comparison of moral concepts, which, in turn, can facilitate and support the goals and methodological underpinnings of both approaches. We illustrated the outputs of using a range of moral theories to articulate and conceptualise the impacts of energy dilemmas. Additionally, we outlined the importance of bearing in mind the substantially different normative framings moral theories provide. We suggest that this method will help energy scholars to identify which approaches are best able to capture the complex and intersecting injustices energy systems pose.

Author Contributions: Conceptualization, N.W. and K.R.; Formal analysis, N.W.; Investigation, N.W.; Methodology, N.W. and K.R.; Project administration, N.W.; Supervision, N.W. and K.R.; Visualization, N.W.; 
Writing-Original draft, N.W.; Writing-Review and editing, N.W. and K.R. All authors have read and agreed to the published version of the manuscript.

Funding: University of Leeds, School of Earth and Environment and Inter-disciplinary Applied Ethics Centre.

Acknowledgments: With thanks to Dr Brand-Correa for useful discussions and feedback. We are also grateful to two anonymous reviewers for their useful and constructive comments.

Conflicts of Interest: The authors declare no conflict of interest.

\section{References}

1. Bickerstaff, K.; Walker, G.; Bulkeley, H. Energy Justice in a Changing Climate: Social Equity and Low-Carbon Energy; Zed Books Ltd.: New York, NY, USA, 2013.

2. McCauley, D.A.; Heffron, R.J.; Stephan, H.; Jenkins, K. Advancing energy justice: The triumvirate of tenets. Int. Energy Law Rev. 2013, 32, 107-110.

3. Sovacool, B.K.; Dworkin, M.H. Global Energy Justice; Cambridge University Press: Cambridge, UK, 2014.

4. Jenkins, K.; McCauley, D.; Forman, A. Energy justice: A policy approach. Energy Policy 2017, 105, 631-634. [CrossRef]

5. Jenkins, K. Setting energy justice apart from the crowd: Lessons from environmental and climate justice. Energy Res. Soc. Sci. 2018, 39, 117-121. [CrossRef]

6. Healy, N.; Stephens, J.C.; Malin, S.A. Embodied energy injustices: Unveiling and politicizing the transboundary harms of fossil fuel extractivism and fossil fuel supply chains. Energy Res. Soc. Sci. 2019, 48, 219-234. [CrossRef]

7. Demski, C.; Thomas, G.; Becker, S.; Evensen, D.; Pidgeon, N. Acceptance of energy transitions and policies: Public conceptualisations of energy as a need and basic right in the united kingdom. Energy Res. Soc. Sci. 2019, 48, 33-45. [CrossRef]

8. Sareen, S.; Haarstad, H. Bridging socio-technical and justice aspects of sustainable energy transitions. Appl. Energy 2018, 228, 624-632. [CrossRef]

9. Jenkins, K.; Sovacool, B.K.; McCauley, D. Humanizing sociotechnical transitions through energy justice: An ethical framework for global transformative change. Energy Policy 2018, 117, 66-74. [CrossRef]

10. Gillard, R.; Snell, C.; Bevan, M. Advancing an energy justice perspective of fuel poverty: Household vulnerability and domestic retrofit policy in the united kingdom. Energy Res. Soc. Sci. 2017, 29, 53-61. [CrossRef]

11. Damgaard, C.; McCauley, D.; Long, J. Assessing the energy justice implications of bioenergy development in nepal. Energy Sustain. Soc. 2017, 7, 8. [CrossRef]

12. Fuller, S.; McCauley, D. Framing energy justice: Perspectives from activism and advocacy. Energy Res. Soc. Sci. 2016, 11, 1-8. [CrossRef]

13. Jenkins, K.; McCauley, D.; Heffron, R.; Stephan, H. Energy justice, a whole systems approach. Queen's Polit. Rev. 2014, 2, 74-87.

14. Jenkins, K.; McCauley, D.; Heffron, R.; Stephan, H.; Rehner, R. Energy justice: A conceptual review. Energy Res. Soc. Sci. 2016, 11, 174-182. [CrossRef]

15. Heffron, R.J.; McCauley, D. The concept of energy justice across the disciplines. Energy Policy 2017, 105, 658-667. [CrossRef]

16. Heffron, R.; McCauley, D.; Sovacool, B. Resolving society's energy trilemma through the energy justice metric. Energy Policy 2015, 87, 168-176. [CrossRef]

17. Heffron, R.J.; McCauley, D. Achieving sustainable supply chains through energy justice. Appl. Energy 2014, 123, 435-437. [CrossRef]

18. Schlosberg, D. Theorising environmental justice: The expanding sphere of a discourse. Environ. Polit. 2013, 22, 37-55. [CrossRef]

19. Schlosberg, D. Defining Environmental Justice: Theories, Movements, and Nature; Oxford University Press: New York, NY, USA, 2009.

20. Fraser, N. Social justice in the age of identity politics: Redistribution, recognition, and participation. The tanner lectures on human values. In Proceedings of the Conferencia dictada en Stanford University, Stanford, CA, USA, 30 April-2 May 1996. 
21. Jenkins, K.; McCauley, D.; Warren, C.R. Attributing responsibility for energy justice: A case study of the hinkley point nuclear complex. Energy Policy 2017, 108, 836-843. [CrossRef]

22. Schlosberg, D. Reconceiving environmental justice: Global movements and political theories. Environ. Polit. 2004, 13, 517-540. [CrossRef]

23. Walker, G. Environmental Justice: Concepts, Evidence and Politics; Routledge: London, UK, 2012.

24. United Nations. The Sustainable Development Goals Report; United Nations: New York, NY, USA, 2018.

25. Sovacool, B.K.; Burke, M.; Baker, L.; Kotikalapudi, C.K.; Wlokas, H. New frontiers and conceptual frameworks for energy justice. Energy Policy 2017, 105, 677-691. [CrossRef]

26. Sovacool, B.K.; Dworkin, M.H. Energy justice: Conceptual insights and practical applications. Appl. Energy 2015, 142, 435-444. [CrossRef]

27. Sovacool, B.K.; Heffron, R.J.; McCauley, D.; Goldthau, A. Energy decisions reframed as justice and ethical concerns. Nat. Energy 2016, 1, 16024. [CrossRef]

28. LaBelle, M.C. In pursuit of energy justice. Energy Policy 2017, 107, 615-620. [CrossRef]

29. Sandel, M.J. Justice: What's the Right Thing to Do? Macmillan: Basingstoke, UK, 2010.

30. Robeyns, I.; Brighouse, H. Introduction: Social Primary Goods and Capabilities as Metrics of Justice. 2010. Available online: https://pdfs.semanticscholar.org/d192/112887f781bd36f2ad06b6844b5d1e8d84c0.pdf (accessed on 13 March 2019).

31. Bentham, J.A. Introduction to the Principles of Morals and Legislation; McMaster University Archive for the History of Economic Thought: Hamilton, ON, Canada, 1781.

32. Crisp, R. Routledge Philosophy Guidebook to Mill on Utilitarianism; Routledge: London, UK, 2002.

33. Mill, J.S. 1969. Utilitarianism. Collect. Works John Stuart Mill. 1861, 10, 203-259.

34. Robeyns, I. The Capability Approach. Available online: https://plato.stanford.edu/archives/win2016/entries/ capability-approach (accessed on 12 September 2019).

35. Robeyns, I. Capabilitarianism. J. Hum. Dev. Capab. 2016, 17, 397-414. [CrossRef]

36. Nussbaum, M.C. Women and Human Development: The Capabilities Approach; Cambridge University Press: Cambridge, UK, 2001; Volume 3.

37. Nussbaum, M. Capabilities as fundamental entitlements: Sen and social justice. Fem. Econ. 2003, 9, 33-59. [CrossRef]

38. Nayak, A.K. Development, displacement and justice in india: Study of hirakud dam. Soc. Chang. 2013, 43, 397-419. [CrossRef]

39. Gururaja, S. Gender dimensions of displacement. Forced Migr. Rev. 2000, 9, 13-16.

40. Robeyns, I. Having too much. In NOMOS LVI: Wealth; Yearbook of the American Society for Political and Legal Philosophy; New York University Press: New York, NY, USA, 2006.

41. Day, R.; Walker, G.; Simcock, N. Conceptualising energy use and energy poverty using a capabilities framework. Energy Policy 2016, 93, 255-264. [CrossRef]

42. Middlemiss, L.; Ambrosio-Albalá, P.; Emmel, N.; Gillard, R.; Gilbertson, J.; Hargreaves, T.; Mullen, C.; Ryan, T.; Snell, C.; Tod, A. Energy poverty and social relations: A capabilities approach. Energy Res. Soc. Sci. 2019, 55, 227-235. [CrossRef]

43. Wood, N.; Roelich, K. Tensions, capabilities, and justice in climate change mitigation of fossil fuels. Energy Res. Soc. Sci. 2019, 52, 114-122. [CrossRef]

44. Milchram, C.; Hillerbrand, R.; van de Kaa, G.; Doorn, N.; Künneke, R. Energy justice and smart grid systems: Evidence from the netherlands and the united kingdom. Appl. Energy 2018, 229, 1244-1259. [CrossRef]

45. Sen, A. Development as Freedom; Oxford Paperbacks: New York, NY, USA, 2001.

46. Nussbaum, M.C. Creating Capabilities; Harvard University Press: Cambridge, MA, USA, 2011.

47. Adger, W.N. Vulnerability. Glob. Environ. Chang. 2006, 16, 268-281. [CrossRef]

48. Rawls, J. A Theory of Justice; Harvard University Press: Cambridge, MA, USA, 1971.

49. Anderson, E.S. What is the point of equality? Ethics 1999, 109, 287-337. [CrossRef]

(C) 2020 by the authors. Licensee MDPI, Basel, Switzerland. This article is an open access article distributed under the terms and conditions of the Creative Commons Attribution (CC BY) license (http://creativecommons.org/licenses/by/4.0/). 